\title{
Efficacy of Cranial Electrotherapy Stimulation Combined with Biofeedback Therapy in Patients with Functional Constipation
}

\author{
Bing Yan Gong, ${ }^{1}$ Hong Mei Ma, ${ }^{2}$ Xiao Ying Zang, ${ }^{1}$ Si Yuan Wang, ${ }^{1}$ Yi Zhang, ${ }^{3}$ Nan Jiang, ${ }^{1}$ Xi Peng Zhang, ${ }^{3}$ and Yue Zhao ${ }^{1 *}$ \\ ${ }^{\text {I} S}$ Shool of Nursing; Tianjin Medical University, Tianjin, China; ${ }^{2}$ Department of Nursing, Nankai University Affiliated Hospital, Tianjin, China; \\ and ${ }^{3}$ Department of Colorectal Surgery, Nankai University Affiliated Hospital, Tianjin, China
}

\section{Background/Aims}

A large number of studies have shown that function constipation (FC) has an extremely high incidence of mental and psychological disorders. Cranial electrotherapy stimulation (CES) was applied to the treatment of psychological disorders such as anxiety and depression. We explored the effects of CES combined with biofeedback therapy (BFT) on the psychological state, clinical symptoms, and anorectal function in patients with FC.

\section{Methods}

A total of 74 patients with FC were randomly divided into 2 groups. The control group received BFT. CES combined with BFT was carried out in the experiment group. All patients were assessed using the self-rating anxiety scale (SAS), self-rating depression scale (SDS), and Wexner constipation score at baseline and the end of each course. Anorectal manometry and balloon expulsion tests were performed before and after treatment.

\section{Results}

After treatment, the participants in the experiment group had significantly lower score SAS, SDS, and Wexner constipation scores than the control group (all $P<0.05)$. The number of successful expulsion in the experiment group was larger than the control group $(P=$ 0.016).

\section{Conclusions}

CES combined with BFT was effective in improving the psychological status of anxiety, depression, and bowel symptoms in patients with FC.

(J Neurogastroenterol Motil 2016;22:497-508)

Key Words

Biofeedback; Constipation; Cranial electrotherapy stimulation; Treatment outcome

Received: May 27, 2015 Revised: January 20, 2016 Accepted: January 27, 2016

(a) This is an Open Access article distributed under the terms of the Creative Commons Attribution Non-Commercial License (http://creativecommons. org/licenses/by-nc/4.0) which permits unrestricted non-commercial use, distribution, and reproduction in any medium, provided the original work is properly cited.

${ }^{*}$ Correspondence: Yue Zhao, PhD

School of Nursing, Tianjin Medical University, 22, QiXiangTai Road, Heping District, Tianjin 300070, China Tel: +86-022-83336901, Fax: +86-022-83336900, E-mail: yuezhao35@hotmail.com 


\section{Introduction}

Constipation is a chronic and common gastrointestinal disorder with a high prevalence. It affects between $0.7 \%$ and $79 \%$ of people around the world, ${ }^{1}$ with a prevalence rangeing from $12 \%$ to $17 \%$ in Western countries, ${ }^{2}$ and $3.19 \%$ to $11.6 \%$ in China. ${ }^{3}$ Functional constipation (FC) is a common functional bowel disorder, manifesting as straining during defecation, lumpy or hard stools, infrequent bowel movements, or incomplete evacuation that does not meet the criteria of irritable bowel syndrome (IBS), in the absence of evident organic or structural diseases. ${ }^{4}$ According to the survey, there is about $6 \%$ of the population suffering from $\mathrm{FC}$ in China. ${ }^{5}$ It may cause gastrointestinal problems such as anal pain, abdominal pain, rectal bleeding, poor appetite, and fecal impaction, or non-gastrointestinal complications such as urinary problems. ${ }^{6-8}$ Although not life-threatening, persistent constipation can profoundly and negatively affect mental state and quality of life, and is associated with a significant economic burden related to direct and indirect annual health-care costs. ${ }^{9,10}$ The current medical treatments for FC include fiber, osmotic and stimulant laxatives, and 5- $\mathrm{HT}_{4}$ agonists. ${ }^{11} \mathrm{How}-$ ever, the effectiveness of these therapies is limited. What is worse, the adverse events result in a long therapeutic course. ${ }^{12}$ Accordingly, more and more patients with FC have focused on biofeedback therapy (BFT), which is a non-medicinal, has no side-effects, and is a noninvasive technology.

BFT is an instrument-based, behavior learning program that uses an equipment to record or amplify a patient's bodily activities and then offers feedback to the patient as visual, auditory, or verbal responses. ${ }^{13}$ The first application of BFT for constipation treatment was reported in 1987. ${ }^{14}$ Recently, studies reported that BFT was effective for patients with dyssynergic defecation, ${ }^{15,16}$ constipated patients with mild spinal cord diseases, ${ }^{17}$ and constipated patients caused by radical hysterectomy or vaginal delivery. ${ }^{18}$ Currently, BFT is regarded as a therapeutic option for patients with $\mathrm{FC}{ }^{19}$

A large number of studies showed that FC patients have abnormal psychological status such as anxiety and depression, ${ }^{20-22}$ which affects gastrointestinal function through the brain-gut axis. ${ }^{23}$ Therefore, the management of psychological disorders has become an important part of the treatment for patients with FC. In recent years, studies found that cranial electrotherapy stimulation (CES) is an effective technique to treat these psychological disorders. It is a noninvasive brain stimulation prescriptive medical treatment. ${ }^{24}$ CES was first cleared for interstate marketing and export by the US Food and Drug Administration (FDA) for the treatment of anxi- ety, depression, and insomnia in 1979. We have therefore assessed the effect of CES combined with BFT in patients with FC, which included bowel symptoms, psychological status, and anorectal function.

\section{Materials and Methods}

\section{Patients}

Patients with FC who visited the Pelvic Floor Center, Nankai University Affiliated Hospital, Tianjin, China, between April 2014 and March 2015 were enrolled. The inclusion criteria included: (1) according with the Rome III diagnostic criteria, ${ }^{25}$ (2) age of at least 18 years, (3) able to communicate effectively, (4) willing to participate and signed informed consent, and (5) recommendation by the physician to receive BFT for constipation (patients with signs of paradoxical or non-relaxing puborectalis relaxation on at least 2 studies including physical exam, defecography, or balloon expulsion test (BET), with signs of internal anal sphincter hypertonia, were considered as candidates for biofeedback). Exclusion criteria included: (1) organic gastrointestinal diseases diagnosed by colonoscopy or barium enema; (2) a history of other serious chronic diseases (diabetes mellitus, hypothyroidism, psychiatric disturbance), previous history of intestinal surgery, or drug abuse; and (3) patients with a pacemaker or implantable cardioverter-defibrillator.

The study was approved by the Institutional Review Board of Tianjin Medical University which confirmed that the study was in accordance with the ethical guidelines.

The IRB approval number was TMuhMEC 2014005. The clinical trial number was ChiCTR-ICR-15006219.

\section{Questionnaires}

The clinical information of the subjects including gender, age, body mass index, marital status, monthly income, sleep quality, complications, underlying comorbidity, some bowel symptoms, and disease course were investigated. Psychological status was evaluated by the self-rating anxiety scale (SAS) ${ }^{26}$ (Supplementary Table 1) and self-rating anxiety depression scale $(\mathrm{SDS})^{27}$ (Supplementary Table 2). These 2 scales have been widely used with adequate reliability and validity. ${ }^{28,29}$ Both of them consist of 20 items and each item is scored on a 4-point Likert scale (1, a little of the time; 2, some of the time; 3 , good part of the time; 4 , most of the time). The score of each item is calculated to obtain an overall score, and the sum multiplied by 1.25 was used as the standard score. The SAS score 50 and SDS score 53 were used as cutoff points for clinical 
anxiety and clinical depression in Chinese populations, respectively. ${ }^{30}$ The higher score indicates higher level of anxiety or depression symptoms.

The Wexner constipation score (WCS) ${ }^{31}$ (Supplementary Table 3) was used to evaluate constipation severity. It contains 8 variables: frequency of bowel movements, painful evacuation, incomplete evacuation, abdominal pain, length of time per attempt, assistance for defecation, unsuccessful attempts for evacuation per 24 hours, and duration of constipation. The score ranges between 0 and 30 , with 0 indicating no symptoms and 30 indicating the most severe constipation.

\section{Anorectal Manometry}

Before anorectal manometric evaluation, bowel preparation was performed with sodium phosphate solution. This testing was performed in the left lateral position with hips and knees bent to $90^{\circ}$. The solid-state, 3-dimensional (3D) manometric assembly (ManoScanTM 3D; Sierra Scientific Instruments, Los Angeles, CA, USA) was used in the evaluation. The 3-dimensional highresolution manometry (3D-HRM) probe is $10 \mathrm{~mm}$ in diameter and the pressure-sensitive part of probe is $64 \mathrm{~mm}$ in length. It has 256 pressure sensors arranged in 16 rows each with 16 circumferential sensors.

Zero and three hundred millimeters of mercury were set at first and last calibration, respectively. The probe was gently inserted into the rectum at 10-15 cm distance caudally from the anal margin after lubrication. During each study, parameters were assessed in the following chronological order: anorectal pressures at rest, during squeeze (3 attempts), and in simulated defecation with an empty rectal balloon. The rectoanal inhibitory reflex and rectal sensations were evaluated simultaneously by progressively inflating the balloon until patients reported severe urgency. The computer recorded threshold volumes for the first sensation, urgency and maximum discomfort. These manometric data were analyzed using the ManoView software.

\section{Balloon Expulsion Test}

About $50 \mathrm{~mL}$ of water was placed in the balloon catheter and the patient was requested to evacuate the balloon. ${ }^{32}$ Expulsion of the balloon within 5 minutes was defined as being successful. ${ }^{33}$

\section{Biofeedback Therapy}

BFT was administered by a specialized therapist (Y.Z.) with experience in this treatment, which consisted of the following steps. ${ }^{17,34}$ First, the therapist provided individualized education to patients about the structure of the anus and rectum, the mechanism of defecation, the gastrocolic reflex, constipation, and the concept of BFT. Second, the therapist helped patients attach electrodes to the lower abdomen and insert an acryl plug into the anal canal. Next, surface electromyography was performed during sham defecation in a semi-supine position. ${ }^{35}$ After these steps, the patients began biofeedback training, using the equipment of MyoTrac 3 (Thought Technology, Ltd, Montreal, Canada), under the instruction of the therapist. BFT was performed 30 minutes during each session, 5 times per week, 10 times per course, for a total of 3 courses. ${ }^{36}$ The patients watched and/or listened to the instructions of the computer to coordinate the movement of the anorectal and abdominal muscles. During the BFT, patients were required to practice when they were at home, using squeezing and relaxing maneuvers for 15 30 minutes every time, 3-5 times per week.

\section{Cranial Electrotherapy Stimulation}

The CES instrument used was Alpha-Stim SCS (Electromedical Products International, Inc, Mineral Wells, TX, USA) (Fig. 1). It provides cranial electrical stimulation by generating bipolar, asymmetric, rectangular waves with a frequency of $0.5 \mathrm{~Hz}$, and a current intensity that can be adjusted continuously between $10 \mu \mathrm{A}$ and 500 $\mu \mathrm{A}$. First, 2 clipped electrodes were placed on the patients' right and left earlobes. Then, the current was adjusted upward from zero until the patient felt a mild tingling sensation and/or dizziness, at which point the current was decreased to just below the reported threshold of sensation. If the patient experienced no sensation, the therapist adjusted the current gradually until the patient perceived a sensation, and then reduced it slightly below that threshold. ${ }^{37}$ In the treatment group, CES was performed in conjunction with BFT, which lasted 30 minutes each time.

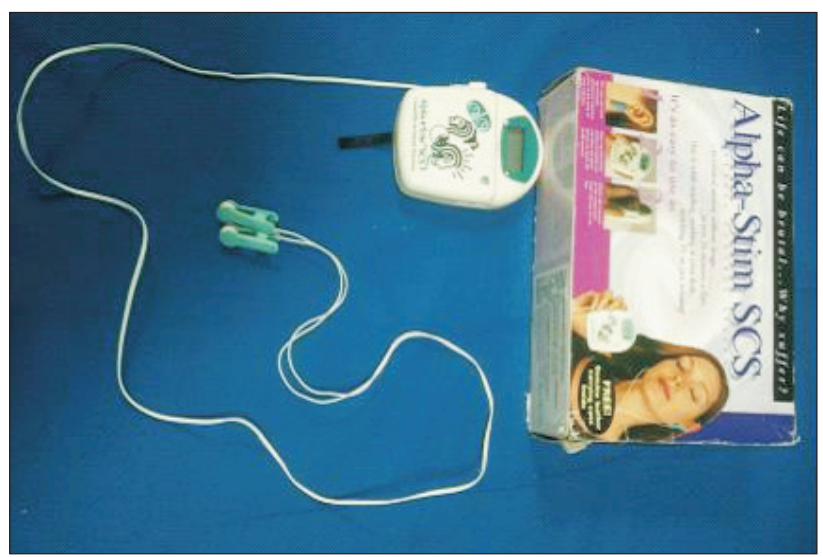

Figure 1. Photo of cranial electrotherapy stimulation instrument. 


\section{Study Design: Protocols}

This was a prospective randomized controlled study. This study involved 2 phases: the run-in period and the treatment period. Before entering the treatment period, all patients were enrolled into a 4 week run-in period to confirm that they met the inclusion criteria. All patients were asked to keep a symptom diary in which they recorded (1) laxative and/or enema use, (2) number of bowel move- ments, (3) straining at stool, (4) feeling of incomplete evacuation, and (5) unassisted bowel movements or assisted bowel movements (defined as bowel movements occurring within 12 hours of taking laxatives or enemas). At the end of the run-in period, the patients' diaries were reviewed. Patients who met the criterion for successful treatment after the run-in phase were excluded from the treatment phase. The remaining patients were randomly assigned to 2 groups. Randomization was achieved by using a computerized random

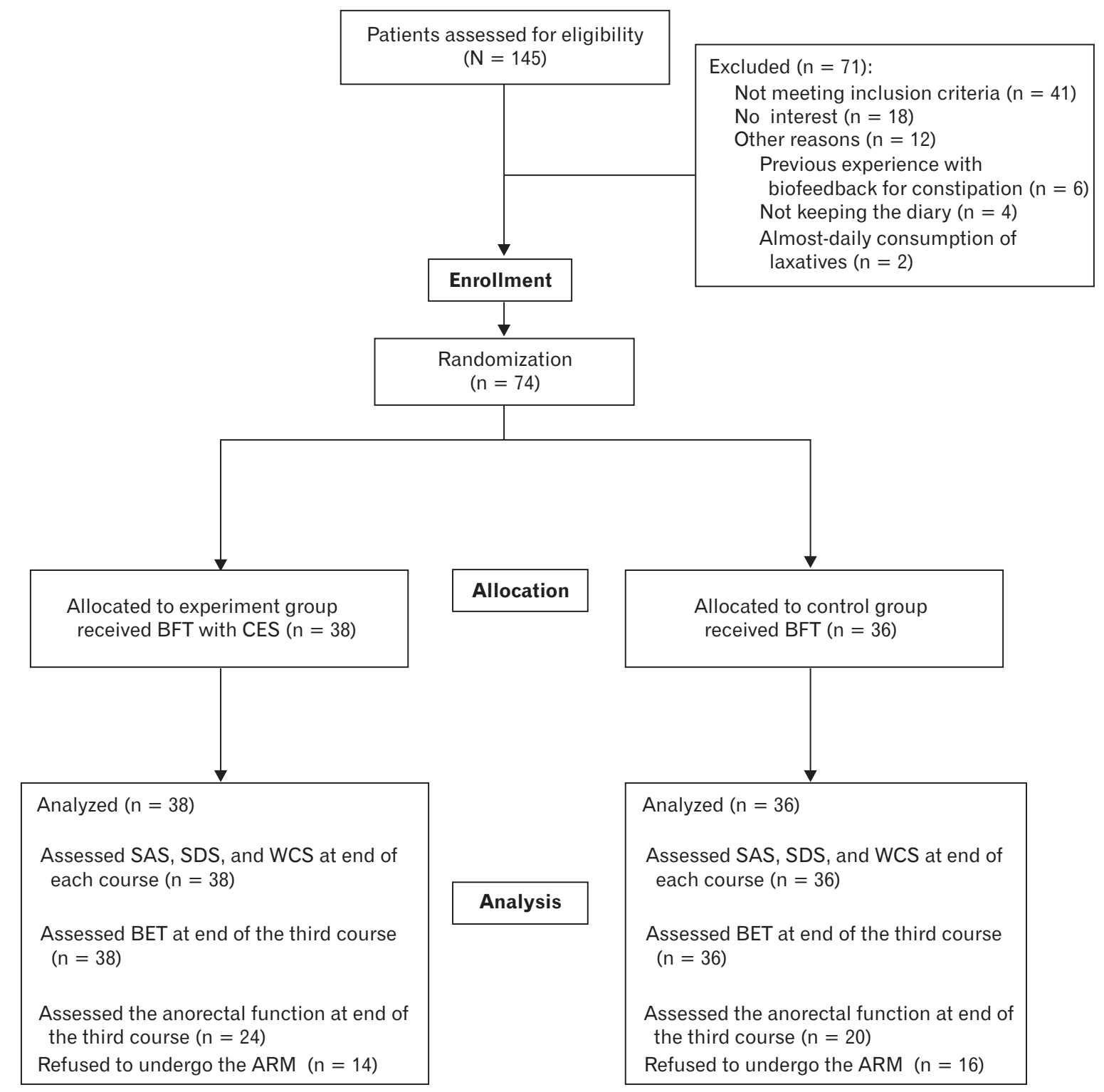

Figure 2. Flow diagram for recruitment and retention of participants for the current study. Of the 145 individuals assessed for eligibility, 74 patients were enrolled in this study. All enrolled patients were randomly divided into 2 groups, 38 patients into the experiment group, 36 patients into the control group. Control group received biofeedback therapy (BFT). Cranial electrotherapy stimulation (CES) combined with BFT was carried out in the experiment group. All patients were assessed using self-rating anxiety scale (SAS), self-rating depression scale (SDS), and Wexner constipation score (WCS) at baseline and at the end of each course. Anorectal manometry (ARM) and balloon expulsion test (BET) was performed before and after treatment. 
Table 1. Baseline Patient Characteristics

\begin{tabular}{|c|c|c|c|c|}
\hline Characteristics & $\begin{array}{l}\text { Experiment group } \\
\qquad(\mathrm{n}=38)\end{array}$ & $\begin{array}{l}\text { Control group } \\
\qquad(\mathrm{n}=36)\end{array}$ & $t$ or $\chi^{2}$ & $P$ \\
\hline Age (mean $\pm \mathrm{SD}, \mathrm{yr})$ & $52.45 \pm 14.38$ & $53.17 \pm 12.11$ & -0.232 & 0.817 \\
\hline Gender (n) & & & 2.044 & 0.194 \\
\hline Male & $13(34.2 \%)$ & $7(19.4 \%)$ & & \\
\hline Female & $25(65.8 \%)$ & $29(80.6 \%)$ & & \\
\hline $\mathrm{BMI}\left(\right.$ mean $\left.\pm \mathrm{SD}, \mathrm{kg} / \mathrm{m}^{2}\right)$ & $23.02 \pm 2.31$ & $23.38 \pm 3.88$ & -0.492 & 0.624 \\
\hline Marital Status (n) & & & 0.816 & 0.889 \\
\hline Unmarried & $3(7.9 \%)$ & $2(5.6 \%)$ & & \\
\hline Married & $29(76.3 \%)$ & $26(72.2 \%)$ & & \\
\hline Divorced & $3(7.9 \%)$ & $5(13.9 \%)$ & & \\
\hline Widowed & $3(7.9 \%)$ & $3(8.3 \%)$ & & \\
\hline Monthly Income (n) & & & 5.194 & 0.164 \\
\hline$\leq 3000$ yuan & $3(7.9 \%)$ & $8(22.2 \%)$ & & \\
\hline 3001-5000 yuan & $13(34.2 \%)$ & $14(38.9 \%)$ & & \\
\hline 5001-10000 yuan & $12(31.6 \%)$ & $5(13.9 \%)$ & & \\
\hline$\geq 10000$ yuan & $10(26.3 \%)$ & $9(25.0 \%)$ & & \\
\hline Sleep Quality (n) & & & 2.567 & 0.680 \\
\hline Very good & $3(7.9 \%)$ & $2(5.6 \%)$ & & \\
\hline Good & $10(26.3 \%)$ & $6(16.7 \%)$ & & \\
\hline General & $17(44.7 \%)$ & $15(41.7 \%)$ & & \\
\hline Poor & $6(15.8 \%)$ & $9(25.0 \%)$ & & \\
\hline Very poor & $2(5.3 \%)$ & $4(11.1 \%)$ & & \\
\hline Complications (n) & & & 2.545 & 0.770 \\
\hline None & $2(5.3 \%)$ & $3(8.3 \%)$ & & \\
\hline Proctitis & $3(7.9 \%)$ & $4(11.1 \%)$ & & \\
\hline Anal fissure & $12(31.6 \%)$ & $7(19.4 \%)$ & & \\
\hline Hemorrhoid & $17(44.7 \%)$ & $20(55.6 \%)$ & & \\
\hline Intestinal obstruction & $2(5.3 \%)$ & $1(2.8 \%)$ & & \\
\hline Angina pectoris & $2(5.3 \%)$ & $1(2.8 \%)$ & & \\
\hline Underlying comorbidity (n) & & & 1.364 & 0.714 \\
\hline None & $16(42.1 \%)$ & $13(36.1 \%)$ & & \\
\hline Diabetes & $9(23.7 \%)$ & $12(33.3 \%)$ & & \\
\hline Hypertension & $11(28.9 \%)$ & $8(22.2 \%)$ & & \\
\hline Abdominopelvic surgery & $2(5.3 \%)$ & $3(8.3 \%)$ & & \\
\hline Complete spontaneous bowel movement (n) & & & 0.207 & 0.649 \\
\hline Yes & $3(7.9 \%)$ & $5(13.9 \%)$ & & \\
\hline No & $35(92.1 \%)$ & $31(86.1 \%)$ & & \\
\hline Frequency of bowel movements (n) & & & 1.741 & 0.628 \\
\hline 3 times or more than 3 times per week & $7(18.4 \%)$ & $9(25.0 \%)$ & & \\
\hline 2 times per week & $16(42.1 \%)$ & $14(38.9 \%)$ & & \\
\hline Once per week & $13(34.2 \%)$ & $9(25.0 \%)$ & & \\
\hline Less than once per week & $2(5.3 \%)$ & $4(11.1 \%)$ & & \\
\hline Straining $(n)$ & & & 0.004 & 0.950 \\
\hline Yes & $36(94.7 \%)$ & $33(91.7 \%)$ & & \\
\hline No & $2(5.3 \%)$ & $3(8.3 \%)$ & & \\
\hline Incomplete evacuation (n) & & & 0.439 & 0.508 \\
\hline Yes & $29(76.3 \%)$ & $24(66.7 \%)$ & & \\
\hline No & $9(23.7 \%)$ & $12(33.3 \%)$ & & \\
\hline Disease course (mean $\pm \mathrm{SD}, \mathrm{yr}$ ) & $8.56 \pm 7.06$ & $10.03 \pm 7.09$ & -0.895 & 0.374 \\
\hline
\end{tabular}


number table. The patients were randomly assigned to 2 groups: the experiment group (CES with BFT) and the control group (BFT). Because of the nature of the intervention, neither participants nor research staff were blinded to allocation. Before the treatment, all patients answered the questionnaires and underwent ARM and BET. At the end of each course, all patients completed the questionnaires and performed BET again. Most patients were reevaluated regarding the anorectal pressure after the third course (Fig. 2).

\section{Safety Assessment}

The safety of CES was recorded by participants at each session. We recorded the number of people who endorsed the side effects rather than number of times a side effect was recorded because it is unclear whether all participants recorded an effect each time it occurred.

\section{Statistical Methods}

All statistical analyses were performed using SPSS version 18.0 (SPSS Inc, Chicago, IL, USA). Continuous variables were presented as mean \pm standard deviation and categorical variables presented as frequencies and proportions. The Chi-squared test was used for comparison of non-continuous parameters (baseline data and BET). The difference of scores (SAS, SDS, and WCS) and the changes of ARM values between the experiment group and the control group before and after treatment were examined with Student's t test. Analysis of temporal changes in scores (SAS, SDS, and WCS) at 4 different time points was performed using repeated measures analysis of variance (ANOVA). All $P$-values reported were two-sided and a $P$-value $<0.05$ was regarded as statistically significant.

\section{Results}

\section{Baseline Characteristics}

As shown in Figure 2, 145 individuals were assessed for eligibility, and 71 patients were excluded. Finally, 74 patients were enrolled in this study. All enrolled patients were randomly divided into 2 groups, 38 patients into the experiment group and 36 patients into the control group. Table 1 shows the baseline patient characteristics. The mean age was 52.45 and 53.17 years in the experiment and control groups, respectively $(P=0.817)$. The proportion of male and female patients were $34.2 \%$ and $65.8 \%$ in the experiment group, $19.4 \%$ and $80.6 \%$ in the control group, respectively $(P=$ 0.194). Body mass index, marital status, monthly income, sleep quality, complications, underlying comorbidity, complete spontaneous bowel movement, frequency of bowel movements, straining, incomplete evacuation, and disease course did not differ between the 2 groups $(P>0.05)$.

\section{Anxiety, Depression, and Bowel Symptom}

A repeated measures ANOVA was used to analyze the change in scores on the SAS, SDS, and WCS from the baseline to endpoint of the study in Table 2. Outcome measurements were conducted at

Table 2. Anxiety, Depression, and Bowel Symptom Change from Baseline to Endpoint of Study

\begin{tabular}{|c|c|c|c|c|c|c|c|}
\hline & Baseline & 1 st course & 2nd course & 3 rd course & & F & $P^{\mathrm{b}}$ \\
\hline SAS & & & & & $\mathrm{G}$ & 4.404 & 0.039 \\
\hline Experiment group $(\mathrm{n}=38)$ & $55.26 \pm 5.83$ & $52.11 \pm 5.48$ & $46.42 \pm 3.94$ & $41.82 \pm 5.31$ & $\mathrm{~T}$ & 101.361 & $<0.001$ \\
\hline Control group $(\mathrm{n}=36)$ & $55.78 \pm 5.46$ & $50.94 \pm 4.71$ & $49.00 \pm 3.84$ & $46.75 \pm 3.71$ & $\mathrm{G} * \mathrm{~T}$ & 10.549 & $<0.001$ \\
\hline$P^{\mathrm{a}}$ & 0.697 & 0.333 & 0.006 & $<0.001$ & & & \\
\hline SDS & & & & & G & 4.813 & 0.031 \\
\hline Experiment group $(\mathrm{n}=38)$ & $58.16 \pm 7.58$ & $53.03 \pm 5.19$ & $47.08 \pm 3.93$ & $43.08 \pm 4.00$ & $\mathrm{~T}$ & 120.737 & $<0.001$ \\
\hline Control group $(\mathrm{n}=36)$ & $57.81 \pm 5.92$ & $52.64 \pm 4.67$ & $50.11 \pm 4.28$ & $48.75 \pm 5.72$ & $\mathrm{G} * \mathrm{~T}$ & 9.338 & $<0.001$ \\
\hline$P^{\mathrm{a}}$ & 0.825 & 0.737 & 0.002 & $<0.001$ & & & \\
\hline WCS & & & & & $\mathrm{G}$ & 13.131 & 0.001 \\
\hline Experiment group $(\mathrm{n}=38)$ & $15.29 \pm 3.42$ & $15.08 \pm 2.66$ & $12.00 \pm 2.72$ & $10.03 \pm 1.98$ & $\mathrm{~T}$ & 85.376 & $<0.001$ \\
\hline Control group $(\mathrm{n}=36)$ & $16.61 \pm 4.07$ & $16.58 \pm 3.29$ & $14.94 \pm 2.69$ & $12.64 \pm 3.04$ & $\mathrm{G} * \mathrm{~T}$ & 2.869 & 0.043 \\
\hline$P^{\mathrm{a}}$ & 0.134 & 0.033 & $<0.001$ & $<0.001$ & & & \\
\hline
\end{tabular}

atudent's $t$ test.

${ }^{\mathrm{b}} \mathrm{ANOVA}$ repeated measures test.

SAS, self-rating anxiety scale; SDS, self-rating depression scale; WCS, Wexner constipation score; G, treatment effect; T, time effect; G*T, interaction between time and treatment.

Data are presented as mean $\pm \mathrm{SD}$. 
the end of each course. Repeated measures ANOVA showed the scores of SAS, SDS, and WCS were significantly different within the groups with time. There were significant differences between the groups for the SAS, SDS, and WCS scores. Significant interaction between treatment groups and time for the scores of SAS, SDS, and WCS indicated a marked difference in the responses of the 2 groups at different intervals with intervention. Means for the SAS, SDS, WCS scores are shown in Figures 3-5, with a decrease in the scores indicating lessening of anxiety, depression, and improving constipation symptom. The SAS decrease in the experiment group of $24.3 \%$ (55.26-41.82) was more than one times the mean decrease on SAS for the control group of 16.2\% (55.78-46.75) from the baseline to endpoint of the study (Fig. 3). The SDS decrease in the experiment group of $25.9 \%$ (58.16-43.08) was more than one times the mean decrease on SDS for the control group of $15.7 \%$ (57.81-48.75) from the baseline to endpoint of the study (Fig. 4). The WCS decrease in the experiment group of 34.4\% (15.2910.03) was more than one times the mean decrease on WCS for the control group of 23.9\% (16.61-12.64) from the baseline to endpoint of the study (Fig. 5).

\section{Anorectal Manometry}

ARM was performed before and after treatment in 44 patients, 24 and 20 in the experiment and control groups, respectively. Manometric findings are summarized in Table 3 . The changes of

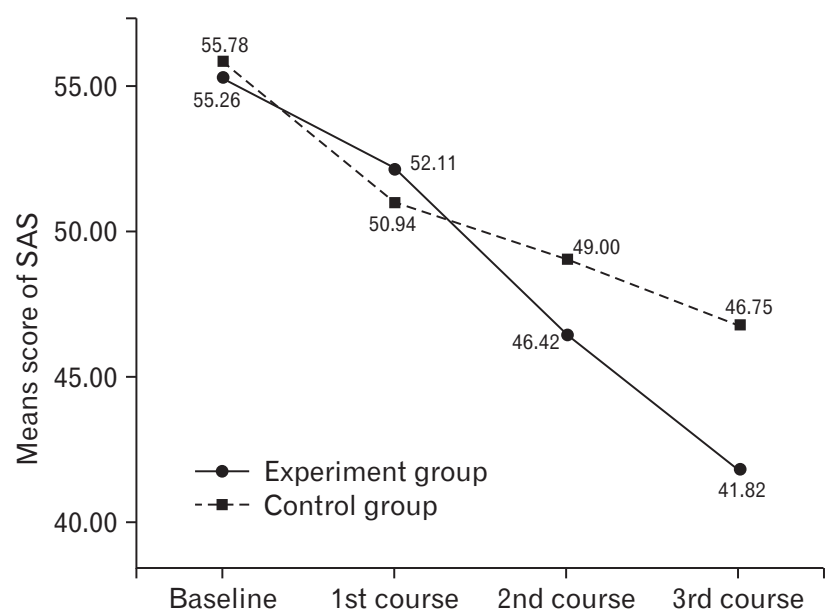

Figure 3. Mean score results of self-rating anxiety scale (SAS) at baseline and the end of each course for experiment and control groups. The mean score of SAS was 55.26 and 55.78 in the experiment and control groups before treatment, respectively. It revealed a score decrease in both groups from pre-treatment to the last course, indicating a lessening of anxiety. Compared with the control group, the experiment group showed greater decrease. all parameters had no significant differences between the 2 groups before and after treatment $(P>0.05)$.

In addition, there were 46 subjects who showed dyssynergia

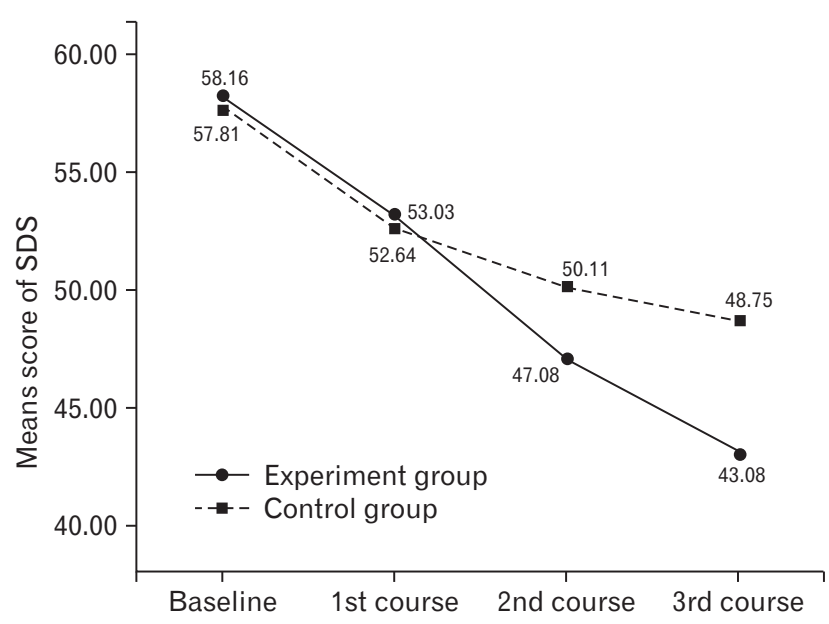

Figure 4. Mean score of self-rating depression scale (SDS) before and after each course for the experiment and control groups are displayed. In the experiment group, the mean score of SDS was 58.16, $53.03,47.08$, and 43.08 before and after each course, respectively. In the control group, the mean score SDS was 57.81, 52.64, 50.11, and 48.75 before and after each course, respectively. It revealed a decrease of the score in both groups from pre-treatment to the post-treatment, indicating a lessening of anxiety. Compared with the control group, the experiment group showed greater decrease.

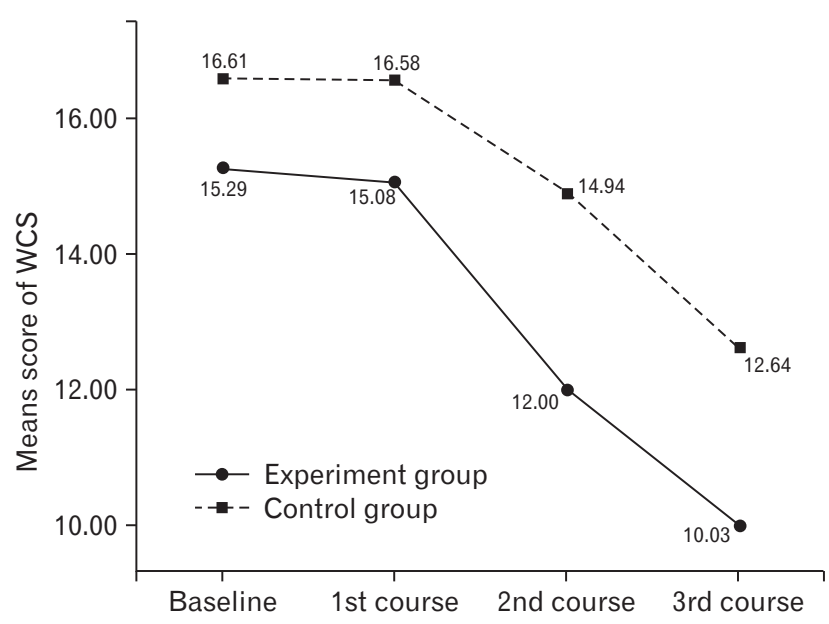

Figure 5. Means score of Wexner constipation score (WCS) before and after each course for experiment and control group. Within each group, average score of WCS changed quite consistently across time, in which the experiment group score was reduced from 15.29 to 10.03, and the control group from 16.61 to 12.64 . The range of reduction in the experiment group was greater than that of the control group. 
Table 3. Anorectal Manometry Values Before and After Treatment

\begin{tabular}{|c|c|c|c|c|}
\hline & $\begin{array}{l}\text { Experiment group } \\
\qquad(\mathrm{n}=24)\end{array}$ & $\begin{array}{l}\text { Control group } \\
\qquad(\mathrm{n}=20)\end{array}$ & $t$ & $P$ \\
\hline \multicolumn{5}{|c|}{ Maximum resting pressure (mmHg) } \\
\hline Pre-treatment & $92.36 \pm 29.94$ & $92.48 \pm 25.76$ & & \\
\hline Post-treatment & $92.76 \pm 22.91$ & $89.42 \pm 22.66$ & -0.600 & 0.553 \\
\hline \multicolumn{5}{|c|}{ Mean resting pressure (mmHg) } \\
\hline Pre-treatment & $81.58 \pm 24.61$ & $85.42 \pm 20.79$ & & \\
\hline Post-treatment & $78.65 \pm 20.09$ & $75.89 \pm 18.21$ & -1.178 & 0.249 \\
\hline \multicolumn{5}{|c|}{ Maximum squeeze pressure (mmHg) } \\
\hline Pre-treatment & $226.40 \pm 64.83$ & $200.44 \pm 63.54$ & & \\
\hline Post-treatment & $202.96 \pm 52.72$ & $177.12 \pm 55.24$ & 0.007 & 0.995 \\
\hline \multicolumn{5}{|l|}{ HPZ length $(\mathrm{cm})$} \\
\hline Pre-treatment & $3.93 \pm 0.60$ & $3.90 \pm 0.70$ & & \\
\hline Post-treatment & $3.91 \pm 0.90$ & $3.74 \pm 0.53$ & -0.529 & 0.599 \\
\hline \multicolumn{5}{|c|}{ Duration of sustained squeeze (sec) } \\
\hline Pre-treatment & $16.26 \pm 4.54$ & $16.05 \pm 4.81$ & & \\
\hline Post-treatment & $15.82 \pm 6.35$ & $16.00 \pm 5.88$ & 0.161 & 0.873 \\
\hline \multicolumn{5}{|c|}{ Residual anal pressure (mmHg) } \\
\hline Pre-treatment & $91.82 \pm 26.29$ & $88.62 \pm 37.37$ & & \\
\hline Post-treatment & $86.90 \pm 35.43$ & $90.75 \pm 30.04$ & 0.576 & 0.568 \\
\hline \multicolumn{5}{|c|}{ Anal relaxation rate $(\%)$} \\
\hline Pre-treatment & $31.25 \pm 12.82$ & $30.75 \pm 18.95$ & & \\
\hline Post-treatment & $31.79 \pm 16.68$ & $33.15 \pm 13.67$ & 0.290 & 0.773 \\
\hline \multicolumn{5}{|c|}{ Intrarectal pressure (mmHg) } \\
\hline Pre-treatment & $46.80 \pm 22.83$ & $56.12 \pm 27.64$ & & \\
\hline Post-treatment & $48.09 \pm 21.28$ & $54.73 \pm 37.48$ & -0.271 & 0.788 \\
\hline \multicolumn{5}{|c|}{ Rectoanal pressure differential ( $\mathrm{mmHg}$ ) } \\
\hline Pre-treatment & $-52.84 \pm 31.81$ & $-37.97 \pm 32.29$ & & \\
\hline Post-treatment & $-43.84 \pm 28.47$ & $-47.26 \pm 28.14$ & -1.782 & 0.082 \\
\hline \multicolumn{5}{|c|}{ First sensation (mL) } \\
\hline Pre-treatment & $44.17 \pm 18.16$ & $47.00 \pm 24.94$ & & \\
\hline Post-treatment & $37.92 \pm 14.44$ & $50.50 \pm 28.00$ & 0.927 & 0.363 \\
\hline \multicolumn{5}{|c|}{ Urge to defecate (mL) } \\
\hline Pre-treatment & $82.50 \pm 25.24$ & $104.00 \pm 42.10$ & & \\
\hline Post-treatment & $70.42 \pm 20.10$ & $84.00 \pm 39.13$ & -0.608 & 0.547 \\
\hline \multicolumn{5}{|c|}{ Maximum tolerable volume (mL) } \\
\hline Pre-treatment & $149.17 \pm 33.48$ & $142.50 \pm 36.69$ & & \\
\hline Post-treatment & $141.25 \pm 34.05$ & $134.50 \pm 39.67$ & -0.006 & 0.995 \\
\hline
\end{tabular}

HPZ, high-pressure zone.

Data are presented as mean \pm SD.

during the push maneuvers in the ARM findings before treatment, 25 and 21 in the experiment group and the control group, respectively. After treatment, 19 and 17 participants showed dyssynergia during the push maneuvers in the ARM findings in the experiment group and the control group, respectively. There were no significant differences between the experiment group and the control group before and after treatment.

\section{Balloon Expulsion Test}

BET was performed before and after treatment in all patients. The tests' findings were summarized in Table 4. Before the treatment, failure of expulsion did not differ between the 2 groups $(P=$ 0.680 ). After the treatment, failure of expulsion was more frequently noted in the control group $(44.4 \%)$ than in the experiment group 
Table 4. Balloon Expulsion Test Before and After Treatment

\begin{tabular}{clccc}
\hline & & $\begin{array}{c}\text { Experiment group } \\
(\mathrm{n}=38)\end{array}$ & $\begin{array}{c}\text { Control group } \\
(\mathrm{n}=36)\end{array}$ & $\chi^{2}$ \\
\hline Pre-treatment & & & & 0.680 \\
& Failure of expulsion & $26(68.4 \%)$ & $23(63.9 \%)$ & 0.170 \\
& Success of expulsion & $12(31.6 \%)$ & $13(36.1 \%)$ & 5.845 \\
Post-treatment & & & $16(44.4 \%)$ & 0.016 \\
& Failure of expulsion & $7(18.4 \%)$ & $20(55.6 \%)$ & \\
& Success of expulsion & $31(81.6 \%)$ & & \\
\hline
\end{tabular}

$(18.4 \%)(P=0.016)$

\section{Adverse Events}

No participant reported any severe side effects. All adverse events were minimal, which included pulsing, tickling, or tingling sensations of the ears $(n=3)$, ear clips too tight $(n=2)$, and drowsiness $(n=1)$. As can be seen, there were no serious study related adverse events.

\section{Discussion}

Recently, most researches have certified that patients with dysfunctions of the gastrointestinal tract have an extremely high incidence of mental and psychological disorders, ${ }^{38}$ which not only affect the bowel symptom, but also result in low quality of life, which brings much burden to the family. In our study, before the treatment, the survey showed a high level of anxiety and depression symptoms in patients with FC. This result was in accordance with a previous study. ${ }^{20}$ It is a concern that many patients with a long history of constipation have to seek medical care repeatedly. BFT is recommended as a first-line non-invasive treatment for those with constipation when patients do not respond to conservative measures such as dietary fiber or fluid intake changes, and are resistant to laxatives. ${ }^{39}$ Patients' psychological status can affect the therapeutic effect of $\mathrm{BFT}^{40}$ A research reported that patients with chronic constipation who had depressive tendencies had a poor effect of BFT. ${ }^{22}$ Therefore, psychological intervention may improve the therapeutic effect of BFT.

CES is an effective method to deal with the psychological problems. A large number of studies revealed that CES was effective in controlling anxiety, depression, and insomnia ubiquitous in pain patients. ${ }^{41-43}$ In our study, during subsequent courses, symptoms of anxiety and depression continued to decrease for the experimental group. At the second course, a leveling effect took place for the control group for both anxiety and depression scores. In the case of the depression scores, the mean trend line increased again for the control group by the final measurement period. It is possible that a study running 4-6 courses would see a return to baseline for both anxiety and depression for the control group. This indicated that CES combined with BFT could effectively improve the psychological condition for patients with FC. At present, it is not fully understood why administering microcurrent electrical stimulation across the head would reduce anxiety and depression status. While some would point to a possible reason that the alternating microcurrent may initially stimulate afferent branches of cranial nerves by earlobe electrodes. Stimulation may initially occur at branches of the facial, glossopharyngeal, and/or the vagus nerves that originate near the electrode placement on the earlobe, then are carried to the brainstem, the thalamus, and finally the cortex. ${ }^{44} \mathrm{CES}$ may cause cortical brain deactivation, producing changes similar to those produced by anxiolytic medications. ${ }^{45}$

Clinically, drugs (including anxiolytics/anti-depressants) may have the same improvement on psychological disturbance similar to $\mathrm{CES}$, but drugs can become habit forming, and also patients can develop a tolerance which results in an increasingly required dosage during treatment. ${ }^{46}$ Moreover, drugs treat patients with psychological disturbances, which can bring out some side effects, such as seizures, confusion, memory loss, hyper-anxiety, and re-emergence of the original symptoms. ${ }^{47} \mathrm{CES}$ is a safe, painless, and noninvasive therapeutic method. It is of a small size such that it can be carried conveniently and can be used repeatedly to save medical resources. What's more, CES lacks moderate or severe adverse events. ${ }^{48}$ However, further research is needed on whether CES is effective for more severe psychological disturbances.

Our study demonstrated a significant decrease in the WCS scores in both the experiment group and the control groups, which suggested that BFT was a successful behavioral treatment for FC and could improve the bowel symptoms of FC effectively. This result was in accordance with a semi experimental study. ${ }^{49}$ Moreover, the WCS decrease in the experiment group was more than one 
times the mean decrease on WCS for the control group from the baseline to endpoint of the study. This implies that CES combined with BFT is useful for improving clinical symptoms of patients with FC. It may be related to neurotransmitters. Abnormalities in the expression and/or function of neurotransmitters in patients with constipation have been demonstrated by immunohistochemistry, immunofluorescence and electrophysiology. ${ }^{50} \mathrm{CES}$ may stimulate regions that regulate neurotransmitter function via the hypothalamic-pituitary axis. ${ }^{45}$ The neurotransmitters act on the interstitial cells of Cajal to produce contractile patterns that create movement through the gut. ${ }^{51}$

Under normal conditions, the intrarectal pressure increases simultaneously as the anal canal pressure decreases due to relaxation of the puborectalis and external anal sphincter during attempted defecation in a healthy person. ${ }^{52}$ Patients with $\mathrm{FC}$ often have normal colonic transit, while abnormal anorectal sensation or paradoxical contraction of the external anal sphincter and puborectalis during defecation result in bowel disorders. ${ }^{53}$ Anorectal sensory function is the foundation in maintaining normal defecation. ${ }^{22}$ In this study, there were no significant differences in the change of all anorectal parameters between 2 groups CES with BFT and BFT only, before and after treatment. So which of the 2 methods CES with BFT and BFT only would have a better effect for patients with FC was not determined. That might be caused by the short intervention time and the not big enough sample size. Hence, future research should increase the sample size and extend the intervention time to discuss whether CES with BFT or only BFT impacts anorectal parameters on patients with $\mathrm{FC}$, and which method is better for patients with FC.

In this study, failure of balloon expulsion was seen less often in the experiment group after the treatment, thus implying that BFT with CES can improve the anorectal function. That may be related to the rectal sensory system. Rectal sensations are transported by both parasympathetic and sympathetic afferent nerves. ${ }^{54}$ It depends on receptors located in the rectal wall, as well as in the pelvic floor. ${ }^{55}$ CES can increase the secretion of the neurotransmitter acetylcholine which is an excitatory neurotransmitter for the digestive tract. ${ }^{56}$ So the increased acetylcholine could produce parasympathetic hormesis and enhance the relaxant effect of the internal anal sphincters, resulting in the decrease in anorectal pressure.

Our study has the following limitations. First, anorectal manometry was not performed in all patients, which may influence the evaluation of anorectal function. Second, the sample size was not large enough and this study lacked long-term follow-up. Third, we used the ARM and BET as objective indexes to evaluate the effect of CES with BFT, and the Bristol stool form and colonic transit study will be assessed in the next study. Fourth, the BFT protocol was different between our and other generalized studies we will compare the effect of the 2 protocols on patients with FC in future research. Furthermore, neither participants nor research staff were blinded to allocation due to the nature of the intervention in this study.

In conclusion, we have found that CES combined with BFT is useful in FC patients, which can improve the patients' psychological status of anxiety and depression, bowel symptom. Moreover, both BFT and CES are safe, painless, and is a noninvasive therapeutic method, which can be widely applied in clinical practice. In future research, the long-term effect is needed to observe, and prospective studies with larger sample size need to be conducted.

\section{Supplementary Materials}

Note: To access the supplementary tables mentioned in this article, visit the online version of Journal of Neurogastroenterology and Motility at http://www.jnmjournal.org/ and at http://dx.doi. org/10.5056/jnm15089.

Acknowledgements: The authors gratefully acknowledge and thank the staff of Nankai University affiliated hospital for their long-time commitment to the study. Furthermore, we would like to thank a teacher of School of Nursing, Tianjin Medical University (Christine Coussell) for her contribution on the language.

\section{Financial support: None.}

\section{Conflicts of interest: None.}

Author contributions: Bing Yan Gong, Yue Zhao, and Xi Peng Zhang contributed to plan the study; Bing Yan Gong, Hong Mei Ma, and Yi Zhang contributed to conduct the study; Bing Yan Gong, Xiao Ying Zang, Si Yuan Wang, and Nan Jiang contributed to collect and interpret data; and Bing Yan Gong and Yue Zhao contributed to draft the manuscript.

\section{References}

1. Mugie SM, Benninga MA, Di Lorenzo C. Epidemiology of constipation in children and adults: a systematic review. Best Pract Res Clin Gastroenterol 2011;25:3-18.

2. Suares NC, Ford AC. Prevalence of, and risk factors for, chronic idiopathic constipation in the community: systematic review and meta- 
analysis. Am J Gastroenterol 2011;106:1582-1591.

3. Zhao M, Tan ZR. Epidemiology of chronic constipation in adults. World Chin J Dig 2014;22:939-944.

4. Longstreth GF, Thompson WG, Chey WD, Houghton LA, Mearin F, Spiller RC. Functional bowel disorders. Gastroenterology 2006; 130:1480-1491.

5. Zhao YF, Ma XQ, Wang R, et al. Epidemiology of functional constipation and comparison with constipation-predominant irritable bowel syndrome: the Systematic Investigation of Gastrointestinal Diseases in China (SILC). Aliment Pharmacol Ther 2011;34:1020-1029.

6. Kocaay P, Eğritaş Ö, Dalgic B. Normal Defecation pattern, frequency of constipation and factors related to constipation in Turkish children 0-6 years old. Turk J Gastroenterol 2011;22:369-375.

7. Paré P, Fedorak RN. Systematic review of stimulant and nonstimulant laxatives for the treatment of functional constipation. Can J Gastroenterol Hepatol 2014;28:549-557.

8. Imanzadeh F, Sayyari AA, Sharifian M, Javaherizadeh H, Aghasi P. Study of factors affecting resolution of urinary tract infection following treatment of constipation in Iranian children who visited a tertiary referral hospital. Prz Gastroenterol 2012;7:78-80.

9. Friedenberg FK, Dadabhai A, Palit A, Sankineni A. The impact of functional constipation on quality of life of middle-aged Black Americans: a prospective case-control study. Qual Life Res 2012; 21:1713-1717.

10. Mohaghegh Shalmani H, Soori H, Khoshkrood Mansoori B, et al. Direct and indirect medical costs of functional constipation: a populationbased study. Int J Colorectal Dis 2011;26:515-522.

11. Ford AC, Moayyedi P, Lacy BE, et al. American College of Gastroenterology monograph on the management of irritable bowel syndrome and chronic idiopathic constipation. Am J Gastroenterol 2014;109(suppl 1): S2-S26.

12. Ford AC, Suares NC. Effect of laxatives and pharmacological therapies in chronic idiopathic constipation: systematic review and meta-analysis. Gut 2011;60:209-218.

13. Lee HJ, Jung KW, Myung SJ. Technique of functional and motility test: how to perform biofeedback for constipation and fecal incontinence. J Neurogastroenterol Motil. 2013;19:532-537.

14. Bleijenberg G, Kuijpers HC. Treatment of the spastic pelvic floor syndrome with biofeedback. Dis Colon Rectum 1987;30:108-111.

15. Heymen S, Scarlett Y, Jones K, Ringel Y, Drossman D, Whitehead WE. Randomized, controlled trial shows biofeedback to be superior to alternative treatments for patients with pelvic floor dyssynergia-type constipation. Dis Colon Rectum 2007;50:428-441.

16. Rao SSC, Seaton K, Miller M, et al. Randomized controlled trial of biofeedback, sham feedback, and standard therapy for dyssynergic defecation. Clin Gastroenterol and Hepatol 2007;5:331-338.

17. Yang DH, Myung SJ, Jung KW et al. Anorectal function and the effect of biofeedback therapy in ambulatory spinal cord disease patients having constipation. Scand J Gastroenterol 2010;45:1281-1288.

18. Park SK, Myung SJ, Jung KW, , et al. Biofeedback therapy for female patients with constipation caused by radical hysterectomy or vaginal delivery. J Gastroenterol Hepatol 2013;28:1133-1140.

19. Lee YY. What's new in the toolbox for constipation and fecal inconti- nence? Front Med (Lausanne) 2014;24:1.

20. Zhou LR, Lin Z, Lin L, Wang MF, Zhang HJ. Functional constipation: implications for nursing interventions. J Clin Nurs 2010;19:1838-1843.

21. Ding MH, Lin Z, Lin L, Zhang HJ, Wang MF. The effect of biofeedback training on patients with functional constipation. Gastroenterol Nurs 2012;35:85-92.

22. Li MM, Ye BX, Tang YR, et al. [Predictors of efficacy of biofeedback therapy in patients with chronic constipation.] Chin J Intern Med 2014;53:40-43. [Chinese]

23. Devanarayana NM, Rajindrajith S. Association between constipation and stressful life events in a cohort of Sri Lankan children and adolescents. J Trop Pediatr 2010;56:144-148.

24. Nardone R, Höller Y, Leis S, et al. Invasive and non-invasive brain stimulation for treatment of neuropathic pain in patients with spinal cord injury: a review. J Spinal Cord Med 2014;37:19-31.

25. Drossman DA. The functional gastrointestinal disorders and the Rome III process. Gastroenterology 2006;130:1377-1390.

26. Zung WW. A rating instrument for anxiety disorders. Psychosomatics 1971;12:371-379.

27. Zung WW. A self-rating depression scale. Arch Gen Psychiat 1965;12: 63-70.

28. Gong Y, Han T, Chen W, et al. Prevalence of anxiety and depressive symptoms and related risk factors among physicians in China: a crosssectional study. Plos One 2014;9: e103242.

29. Ding YW, Qu JW, Yu XS, Wang S. The mediating effects of burnout on the relationship between anxiety symptoms and occupational stress among community healthcare workers in China: a cross-sectional study. Plos One 2014;9:e107130.

30. Chen SB, Hu H, Gao YS, He HY, Jin DX, Zhang CQ. Prevalence of clinical anxiety, clinical depression and associated risk factors in chinese young and middle-aged patients with osteonecrosis of the femoral head. Plos One 2015;10:e0120234.

31. Agachan F, Chen T, Pfeifer J, Reissman P, Wexner SD. A constipation scoring system to simplify evaluation and management of constipated patients. Dis Colon Rectum 1996;39:681-685.

32. Lee BE, Kim GH. How to perform and interpret balloon expulsion test. J Neurogastroenterol Motil 2014;20:407-409.

33. Jung KW, Yang DH, Yoon IJ, et al. Electrical stimulation therapy in chronic functional constipation: five years' experience in patients refractory to biofeedback therapy and with rectal hyposensitivity. J Neurogastroenterol Motil 2013;19:366-373.

34. Lee BH, Kim N, Kang SB, et al. The long-term clinical efficacy of biofeedback therapy for patients with constipation or fecal incontinence. J Neurogastroenterol Motil 2010;16:177-185.

35. Chen HL, Wang Q, Chen HM. Biofeedback treatment of functional constipation: 188 cases. Chinese J Integrated Traditional Western Med 2013;19:177-179.

36. Lu ZQ, Li JN, Zhuang RF. Application value of biofeedback electrical stimulation in patients with anismus constipation. Mil Med J S Chin 2014;28:449-451.

37. Qiao IP, Weng SH, Wang PW, Long J, Wang ZS. Normalization of intrinsic neural circuits governing tourette's syndrome using cranial elec- 
trotherapy stimulation. IEEE Trans Biomed Eng 2015;62:1272-1280.

38. Portincasa P, Moscbetta A, Baldassarre G, Altomare DF, Palasciano G. Pan-enteric dysmotility, impaired quality of life and alexithymia in a large group of patients meeting ROME II criteria for irritable bowel syndrome. World J Gastroenterol 2003;9:2293-2299.

39. Storrie JB. Biofeedback: a first-line treatment for idiopathic constipation. Br J Nurs 1997;6:152-158.

40. Mason HJ, Serrano-Ikkos E, Kamm MA. Psychological state and quality of life in patients having behavioral treatment (biofeedback) for intractable constipation. Am J Gastroenterol 2002;97:3154-3159.

41. Kirsch DL, Smith RB. The use of cranial electrotherapy stimulation in the management of chronic pain: a review. Neuro Rehabilitation 2000;14:85-94.

42. Klawansky S, Yeung A, Berkey C, Shah N, Phan H, Chalmers TC. Meta-analysis of randomized controlled trials of cranial electrostimulation. Efficacy in treating psychological and physiological conditions. J Nerv Ment Dis 1995;183:478-484.

43. Bystritsky A, Kerwin L, Feusner J. A pilot study of cranial electrotherapy stimulation for generalized anxiety disorder. J Clin Psychiatry 2008;69:412-417.

44. Feusner JD, Madsen S, Moody TD, et al. Effects of cranial electrotherapy stimulation on resting state brain activity. Brain Behav 2012;2:211220.

45. Kirsch DL, Nichols F. Cranial electrotherapy stimulation for treatment of anxiety, depression, and insomnia. Psychiatr Clin North Am 2013;36:169-176.

46. Alramadhan E, Hanna MS, Hanna MS, Goldstein TA, Avila SM, Weeks BS. Dietary and botanical anxiolytics. Med Sci Monit 2012;18:RA40-RA48.
47. Cloos JM, Ferreira V. Current use of benzodiazepines in anxiety disorders. Curr Opin Psychiatry 2009;22:90-95.

48. Moreno-Duarte I, Morse LR, Alam M, Bilkson M, Zafonte R, Freqni F. Targeted therapies using electrical and magnetic neural stimulation for the treatment of chronic pain in spinal cord injury. Neuroimage 2014;85(Pt 3):1003-1013.

49. Ahadi T, Madjlesi F, Mahjoubi B, et al. The effect of biofeedback therapy on dyssynergic constipation in patients with or without irritable bowel syndrome. J Res Med Sci 2014;19:950-955.

50. Porter AJ, Wattchow DA, Hunter A, Costa M. Abnormalities of nerve fibers in the circular muscle of patients with slow transit constipation. Int J Colorectal Dis 1998;13: 208-216.

51. Kirsch DL. Cranial S, DiBaise J, Crowel MD. Irritable bowel syndrome and chronic constipation: emerging drugs, devices, and surgical treatments. Curr Gastroenterol Rep 2006;8:282-290.

52. Öztürk R, Rao SSC. Defecation disorders: an important subgroup of functional constipation, its pathophysiology, evaluation and treatment with biofeedback. Turk J Gastroenterol 2007;18:139-149.

53. Mu Y, Wang SH, Yao J, Wang Y, Liu JF, Niu SJ. Report of 41 cases of functional bowel disorders constipation with biofeedback therapy. J Colorectal \& Anal Surg 2014;20:10-13.

54. Luukkonen P, Mikkonen U, Jarvinen H. Abdominal rectopexy with sigmoidectomy vs. Rectopexy alone for rectal prolapse: a prospective, randomized study. Int J Colorectal Dis 1992;7:219-222.

55. Gosselink MJ, Schouten WR. Rectal sensory perception in females with obstructed defecation. Dis Colon Rectum 2001;44:1337-1344.

56. Shealy YF. Synthesis and evaluation of some new retinoids for cancer chemoprevention. Prev Med 1989;18:624-645. 